\title{
Isolation of NDM-1-producing Pseudomonas aeruginosa sequence type ST235 from a stem cell transplant patient in Italy, May 2013
}

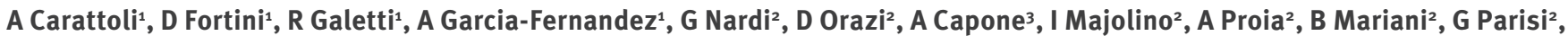

A Morrone ${ }^{2}$, N Petrosillo (nicola.petrosillo@inmi.it) 3

1. Istituto Superiore di Sanità, Rome Italy

2. Azienda Ospedaliera S.Camillo-Forlanini Hospital, Rome Italy

3. National Institute of Infectious Disease “L. Spallanzani”, Rome Italy

Citation style for this article:

Carattoli A, Fortini D, Galetti R, Garcia-Fernandez A, Nardi G, Orazi D, Capone A, Majolino I, Proia A, Mariani B, Parisi G, Morrone A, Petrosillo N. Isolation of NDM1-producing Pseudomonas aeruginosa sequence type ST235 from a stem cell transplant patient in Italy, May 2013. Euro Surveill. 2013;18(46):pii=20633. Available online: http://www.eurosurveillance.org/ViewArticle. aspx?Articleld=20633

Article submitted on 25 October 2013 / published on 14 November 2013

We describe the first isolation of an NDM-1-producing Pseudomonas aeruginosa in Italy. In May 2013, a patient with acute lymphoblastic leukaemia and history of prior hospitalisation in Belgrad, Serbia, underwent stem cell transplantation at a tertiary care hospital in Rome, Italy. After transplantion, sepsis by NDM-1-producing $P$. aeruginosa occurred, leading to septic shock and fatal outcome.

In May 2013, a Pseudomonas aeruginosa strain producing New Delhi metallo-beta-lactamase-1 (NDM-1) was isolated in Italy from a patient previously hospitalised in Serbia and found to be resistant to all antibiotics tested except colistin. Multidrug-resistant and extensively drug-resistant $P$. aeruginosa represent an increasing therapeutic challenge worldwide. In particular, the ST235 clone is the founder of the successful epidemic clonal complex 235 (CC235), associated with various carbapenemase genes, but very rarely with NDM-1 $[1,2]$.

\section{Case description}

In late May 2013, a man in his early 40 s with a diagnosis of acute lymphoblastic leukaemia (ALL) in first remission was admitted to the haematology unit of a hospital in Rome, Italy, in order to undergo stem cell transplantation. He had been hospitalised in December 2012 at a general hospital in Belgrad, Serbia. In that hospital, the patient had undergone four courses of chemotherapy (HYPER-C-VAD) from December 2012 to February 2013 with a complete remission of disease.

At hospital admission in Rome, the patient was febrile, in good general condition. According to the haematology ward's routine procedure adopted for transplantation candidates, nasal, pharyngeal, rectal and groin swabs, as well as blood, urine and stool cultures were screened and found negative for multidrug-resistant bacteria. In brief, all samples were screened for methicillin-resistant Staphylococcus aureus (MRSA), extended-spectrum beta-lactamase (ESBL)-producing Enterobacteriaceae, Acinetobacter baumannii, P. aeruginosa, carbapenem-resistant Enterobacteriaceae, vancomycin-resistant Enterococcus faecium (VRE), using MacConkey and chromogenic agar plates (Becton Dickinson, Heidelberg, Germany). Antimicrobial drug susceptibility testing and minimal inhibitory concentrations (MICs) were obtained by the Phoenix System (Becton Dickinson, Sparks, MD) and interpreted according to the recommendations from the European Committee on Antimicrobial Susceptibility Testing (EUCAST) [3].

Lacking an available HLA-compatible donor, the patient received on 28 May a stem cell transplant from a haploidentical donor, with a high-dose conditioning regimen containing thiotepa, busulfan, and also containing fludarabine-unmanipulated bone marrow as the stem cell source. Prophylaxis of graft-versus-host disease was post-transplant cyclophosphamide, mycophenolate and cyclosporine, as in the Baltimore programme [4].Two days later he developed severe neutropenia (absolute neutrophil count $(\mathrm{ANC})=0.1 \times 10^{9} / \mathrm{L}$ ) and treatment was started with piperacillin/tazobactam, amikacin and vancomycin, with an immediate defervescence. The patient remained neutropenic (ANC $<0.1 \times 10^{9} / \mathrm{L}$ ), and fever reappeared some days later. Meropenem was added in substitution of piperacillin/tazobactam.

A pharyngeal swab taken 10 days after transplantation was positive for Klebsiella pneumoniae. Species identification and antimicrobial susceptibilities were determined by the Phoenix System (Becton Dickinson, Sparks, MD) and the tigecycline MIC was obtained by Etest (Becton-Dickinson, United States). The K. pneumoniae isolate was an ESBL producer with resistance to cefotaxime (MIC >4 mg/L) ceftazidime (MIC $>8 \mathrm{mg} / \mathrm{ml}$ ), ertapenem (MIC >1 $\mathrm{mg} / \mathrm{L}$ ) and tigecycline 


\section{TABLE}

Susceptibility pattern of NDM-1-positive Pseudomonas aeruginosa isolated from blood cultures and perianal abscess, Rome, May 2013

\begin{tabular}{|l|c|}
\hline Antibiotics & MIC $(\mu \mathrm{g} / \mathrm{mL})$, interpretation result ${ }^{a}$ \\
\hline Amikacin & $>16, \mathrm{R}$ \\
\hline Aztreonam & \multicolumn{1}{|c|}{$>16, \mathrm{R}$} \\
\hline Cefepime & $>8, \mathrm{R}$ \\
\hline Ceftazidime & $>1, \mathrm{R}$ \\
\hline Ciprofloxacin & $\leq 1, \mathrm{~S}$ \\
\hline Colistin & $>4, \mathrm{R}$ \\
\hline Gentamicin & $>8, \mathrm{R}$ \\
\hline Imipenem & $>2, \mathrm{R}$ \\
\hline Levofloxacin & $>8, \mathrm{R}$ \\
\hline Meropenem & $>16, \mathrm{R}$ \\
\hline Piperacillin & $>16 / 4, \mathrm{R}$ \\
\hline Piperacillin/tazobactam & $>4, \mathrm{R}$ \\
\hline Tobramycin & \\
\hline
\end{tabular}

MIC: minimum inhibitory concentration R: resistant; S: susceptible a Based on EUCAST interpretive criteria [1].

(MIC $3 \mathrm{mg} / \mathrm{L}$ ), but remained susceptible to imipenem (MIC $\leq 1 \mathrm{mg} / \mathrm{L}$ ), meropenem (MIC $\leq 1 \mathrm{mg} / \mathrm{L}$ ) and colistin (MIC $\leq 1 \mathrm{mg} / \mathrm{L}$ ), according to interpretive criteria from the EUCAST [3]. The strain was assigned to ST101 by multilocus sequence typing [5] and resulted negative for carbapenemase genes in PCR using previously described primers and protocols [6,7]. Colistin (given every 12 hours for a total daily dose of 9,000,000 IU after a loading dose of 9,000,000 IU) was added to the ongoing antimicrobial treatment.

At Day 15 after transplantation, the patient was still febrile and neutropenic. Another rectal swab was again positive for the ertapenem-resistant $K$. pneumoniae. A perianal abscess appeared on Day 16 and draining yielded $P$. aeruginosa and VRE. This isolate was resistant to all antibiotics tested (Table) except colistin.

The blood cultures of the patient, taken on Day 15 yielded a $P$. aeruginosa with an identical phenotype. Vancomycin treatment was halted, and tigecycline (200 mg/day administered every 12 hours, after a loading dose of $200 \mathrm{mg}$ ), rifampicin (600 mg given every 24 hours) and daptomycin (700 mg every 24 hours), were added to the previous treatment.

On Day 17 after transplantation, the patient rapidly deteriorated and was transferred to the intensive care unit, where he died few hours later from septic shock still in profound aplasia.
Molecular characterisation of

the $P$. aeruginosa isolate

The $P$. aeruginosa strain isolated from the blood cultures was identified as sequence type (ST) 235 by MLST [8]. The ST235 strain resulted positive for the $b a_{\mathrm{NDM}-1}$ gene. Plasmid and total DNA was tested by Southern blot hybridisation with the $b / a_{\text {NDM-1 }}$ gene as probe. Results suggested a chromosomal location of the bla $a_{\mathrm{NDM}-1}$ gene (data not shown). Total DNA was restricted with HindIII and a genome library was constructed in the HindIII-pZErO-2 kanamycin-resistant vector (Invitrogen, Milan Italy). Transformants were obtained selecting on plates containing $30 \mathrm{mg} / \mathrm{L}$ ampicillin and $30 \mathrm{mg} / \mathrm{L}$ kanamycin. One transformant carried a HindIII insert of approximately $3.3 \mathrm{~KB}$, which resulted positive in a PCR for the bla $a_{\text {NDM-1 }}$ gene. The insert was fully sequenced using universal primers and the primer walking approach. Comparative DNA sequence analysis showed that the HindlII insert in our construct had $100 \%$ of DNA identity to the Hindlll-fragment of the ST235 P. aeruginosa strain HIABP11(EMBL ACC. No. $\mathrm{KC}_{170992)}$ carrying $b a_{\mathrm{NDM}-1}$ that was isolated in France in March 2012 [9]. Based on the DNA sequence of the HIABP11 strain (EMBL ACC No. KC170992), 12,762 kb containing the entire $b a_{\text {NDM-1 }}$ gene environment and flanking regions were analysed by PCR and sequencing. The presence of ISPa7 was identified upstream of a complex class 1 integron, carrying the aacA7, aadA6, orfD gene cassettes, suggesting a chromosomal location of this genetic determinant. The $b a_{\text {NDM-1 }}$ gene was embedded in the same genetic environment previously described for the HIABP11 ST235 P. aeruginosa isolate from France [9].

\section{Control measures}

\section{The ST235 strain could represent a serious risk for potential spreading in the hospital environment.}

However, during the hospitalisation and after the identification of the strain, strict contact isolation precautions (CIP), and screening of the personnel were implemented on the haematology ward. CIP included wearing a gown and gloves when entering the patient's room, promptly removing gloves after care and hand decontamination, as well as using disposable singleuse or patient dedicated non-critical equipment such as blood pressure cuff and stethoscope. Moreover, since the hands of healthcare workers are the most common vehicle for the transmission of microorganisms, including $P$. aeruginosa and $K$. pneumoniae, from patient to patient and within the healthcare environment [10], hand hygiene practices were strengthened.

All contacts, room-mates, relatives, and personnel involved in the care of the patient were screened for carriage of this organism. In addition, environmental screening for Pseudomonas and Klebsiella was performed at several points of the ward, including the rooms where the patient stayed. Neither NDM-1producing $P$. aeruginosa nor Klebsiella were obtained 
from these cultures. Moreover, after a one month of strict surveillance, neither any infection nor any colonisation by NDM-1-producing $P$. aeruginosa or Klebsiella were observed on the wards where the patient stayed.

\section{Discussion}

It has been recently demonstrated that the emergence of multidrug-resistant, metallo-beta lactamase (MBL)positive $P$. aeruginosa in Russia was largely due to the spread of one dominant clone, CC235 producing VIM-2 [1]. The association of CC235 with MBL genes has been reported outside Russia in several European countries [1]. In particular, VIM-1 was the more common MBL identified in CC235 P. aeruginosa from Italy, VIM-4 in Greece, Sweden, Hungary, and Belgium, VIM-13 in Spain, and IMP-29 in France [1]. To the best of our knowledge, only few NDM-1-producing $P$. aeruginosa strains were reported in Europe before this Italian case: two strains were described in Serbia in $\mathbf{2 0 1 0}$ and one strain was identified in France in 2012 [2,9]. Both the Italian and French NDM-1 producing $P$. aeruginosa were identified in patients previously hospitalised in Serbian hospitals, where a reservoir of NDM-1-producing CC235 $P$. aeruginosa can be suspected. Moreover, six of 55 travel-associated cases of Enterobacteriaceae producing NDM-1 reported in European countries had a link to the Balkan region, presumably to Serbia, Kosovo*, Montenegro, and Bosnia and Herzegovina [11].

* This designation is without prejudice to positions on status, and is in line with United Nations Security Council Resolution $1244 / 99$ and the International Court of Justice Opinion on the Kosovo declaration of independence.

\section{Acknowledgements}

This work was supported by The Italian FLAGSHIP "InterOmics" project (PB.Po5) funded by MIUR and coordinated by the CNR. Renata Galetti's fellowship was supported by the grant 2012/24864-1, Sao Paulo Research Foundation (FAPESP)

Conflict of interest

None declared.

Authors' contributions

All authors of this research paper have directly participated in the planning, execution and analysis of this study

\section{References}

1. Edelstein MV, Skleenova EN, Shevchenko OV, D’souza JW, Tapalski DV, Azizov IS, et al. Spread of extensively resistant VIM-2-positive ST235 Pseudomonas aeruginosa in Belarus, Kazakhstan, and Russia: a longitudinal epidemiological and clinical study. Lancet Infect Dis. 2013;13(10):867-76. http://dx.doi.org/10.1016/S1473-3099(13)70168-3

2. Jovcic B, Lepsanovic Z, Suljagic V, Rackov G, Begovic J, Topisirovic L, et al. Emergence of NDM-1 Metallo-betaLactamase in Pseudomonas aeruginosa Clinical Isolates from Serbia. Antimicrob. Agents Chemother. 2011;55(8):3929-31. http://dx.doi.org/10.1128/AAC.00226-11 PMid:21646490 PMCid:PMC3147624

3. European Committee on Antimicrobial Susceptibility Testing (EUCAST). Breakpoint tables for interpretation of MICs and zone diameters. Version 3.1 EUCAST; 2013. Available from: http://www.eucast.org/clinical-breakpoints/

4. Fuchs El. Human leukocyte antigen-haploidentical stem cell transplantation using T-cell-replete bone marrow grafts. Curr Opin Hematol. 2012;19(6):440-7. http://dx.doi.org/10.1097/MOH.obo13e32835822dc PMid:22954723

5. Diancourt L, Passet V, Verhoef J, Grimont PA, Brisse S. Multilocus sequence typing of Klebsiella pneumoniae nosocomial isolates. J Clin Microbiol. 2005;43(8):4178-82. http://dx.doi.org/10.1128/JCM.43.8.4178-4182.2005 PMid:16081970 PMCid:PMC1233940

6. Yong D, Toleman MA, Giske CG, Cho HS, Sundman K, Lee K, et al. Multiplex PCR for rapid detection of genes encoding acquired metallo-beta-lactamases. J Antimicrob Chemother. 2007;59(2):321-2.

7. Poirel L, Walsh TR, Cuvillier V, Nordmann P. Multiplex PCR for detection of acquired carbapenemase genes. Diagn Microbiol Infect Dis.2011;70(1):119-23.

http://dx.doi.org/10.1016/j.diagmicrobio.2010.12.002 PMid:21398074

8. Curran B, Jonas D, Grundmann H, Pitt T, Dowson CG. Development of a multilocus sequence typing scheme for the opportunistic pathogen Pseudomonas aeruginosa. J. Clin. Microbiol. 2004;42(12):5644-9.

http://dx.doi.org/10.1128/JCM.42.12.5644-5649.2004 PMid:15583294 PMCid:PMC535286

9. Janvier F, Jeannot K, Tessé S, Robert-Nicoud M, Delacour H, Rapp C, et al. Molecular Characterization of blaNDM-1 in a Sequence Type 235 Pseudomonas aeruginosa Isolate from France. Antimicrob. Agents Chemother. 2013; 57(7):3408-11. http://dx.doi.org/10.1128/AAC.02334-12 PMid:23612200

10. Monistrol O, López ML, Riera M, Font R, Nicolás C, Escobar $M A$, et al. Hand contamination during routine care in medical wards: the role of hand hygiene compliance. J Med Microbiol. 2013;62(Pt 4):623-9.

http://dx.doi.org/10.1099/jmm.0.050328-0 PMid:23329322

11. Struelens MI, Monnet DL, Magiorakos AP, Santos O'Connor F, Giesecke J. New Delhi metallo-beta-lactamase 1-producing Enterobacteriaceae: emergence and response in Europe. Euro Surveill. 2010;15(46): pii=19716. Available from: http://www. eurosurveillance.org/ViewArticle.aspx?Articleld=19716 